their therapy. The cost and resource implications of continuing with this therapy need to be addressed.

\section{FRI0039 AN ASSESSMENT OF LEFLUNOMIDE FOR PATIENTS WITH RHEUMATOID ARTHRITIS TREATED IN ROUTINE CLINICAL PRACTICE}

JA Teir, AD Woolf, MJ Davis. Rheumatology, Royal Cornwall Hospital, Truro, Cornwall, England, UK

\subsection{6/annrheumdis-2001.1168}

Background Phase 3 clinical trails used for licensing of new agents are not always reflective of 'day to day' clinical practice. Objectives We have examined the use and effect of Leflunomide in the routine clinic situation.

Methods From December 1999 until May 200020 patients with rheumatoid arthritis commenced on Leflunomide had a full clinical assessment in a general rheumatology clinic. All had joint scores (28 swelling and tenderness), health assessment questionnaire (HAQ), VAS pain, patient and physician global and C-reactive protein (CRP) measured at initiation of treatment and follow up visit. joint scores were performed by clinic nurses, 5 in total, given basic training in the technique. the mean follow up was 6 months (2-9 months) with the above the American College of rheumatology (ACR) criteria for response was calculated. Results At final assessment the mean SJC had reduced from 14.5 to 11.0 ( $\mathrm{p}<0.02$ ), mean TJC 14.1 to 10.0 ( $\mathrm{p}<0.02$ ), mean CRP 55.3 to $30(\mathrm{p}<0.01)$ and mean HAQ from 2.3 to 2.2 (p $<0.9)$. Only $5(25 \%)$ however achieved an ACR20 of which 2 were ACR50. At mean follow up of 6 months 7(35\%) had discontinued treatment because of adverse reaction. 6 were as a result of bowel disturbance and 1 because of headache. in this small group no patients had serious abnormalities in either their liver function or full blood counts. 13(65\%) were continuing with therapy content with its efficacy.

Conclusion The ACR 20 response is clearly less than the published trails (52\%) yet the perceived patient efficacy is similar. The difference related to the difficulty in performing, reliably, the joint scores in routine clinical practice. this ought to considered when suggesting these measures should be performed outside of the research setting. The incidence of bowel upset is higher than the phase 3 study (13\%). This may be attributable to different patient populations with fewer exclusion criteria in clinical practice.

\section{REFERENCE}

1 Smolen JS, et al. Lancet 1999;353:259-66

\section{FRIO040 HELICOBACTER PYLORI INFECTION AND NSAIDS GASTRIC LESIONS IN PATIENTS WITH RHEUMATOID ARTHRITIS}

${ }^{1} \mathrm{~F}$ Montrone, ${ }^{2} \mathrm{M}$ Lazzaroni, ${ }^{1} \mathrm{M}$ Antivalle, ${ }^{1} \mathrm{~S}$ Santandrea, ${ }^{1} \mathrm{G}$ Bianchi Porro, ${ }^{1} \mathrm{M}$ Carrabba. ${ }^{1}$ Rheumatology Unit; ${ }^{2}$ Gastroenterology Unit, Ospedale L. Sacco, Milano, Italy

\subsection{6/annrheumdis-2001.1169}

Background Helycobacter pylori is present in about fifty percent of patients with NSAIDs associated gastric lesions. However, studies on the interaction between $\mathrm{H}$. pylori and the occurrence of NSAIDs gastrotoxicity have yielded conflicting results.

Objectives To investigate the correlation between $\mathrm{H}$. pylori infection and the development of NSAIDs related gastric lesions.
Methods Data were collected during our double blind clinical and gastroscopic study on the treatment of rheumatoid arthritis with diclofenac or amtolmetinguacyl. A total of 64 patients, aged 18-80 years, suffering from rheumatoid arthritis were randomised to diclofenac $(50 \mathrm{mg}$ tid) or amtolmetinguacyl 600 $\mathrm{mg}$ bid) for 4 weeks. Clinical and endoscopic evaluation were performed at baseline and at the end of the treatment.

The gastroduodenal mucosa was graded according to the Lanza scale, and H. pylori status was assessed at baseline by histology ( 2 biopsy samples in the antrum, one at the augulus and two in the body of the stomach) and by rapid urease test (one sample in the gastric antrum).

Results All but one of the patients reached the final visit and 59 underwent endoscopy. H. pylori infection was detected in 30 of the 59 patients (51\%); this prevalence is not significantly different from the age-adjusted rate for control populations in western countries and is consistent with previous reports in rheumatoid arthritis and in arthritides of different aetiology. The gross appearance of gastroduodenal mucosa was graded as follows: grade 0 , normal mucosa; grade 1 , mucosal haemorrhage only; grade 2, one or two erosions; grade 3, numerous areas (3-10) of erosions; grade 4 , large number of erosions $(>10)$ or an ulcer. Considering together patients with endoscopic grading $0-1-2$ (normal or minimal lesions) and grading 3-4 (numerous erosions or ulcer), $6 / 30(20 \%)$ of the $H$. pylori positive patients and 9/29 $(31 \%)$ of the $\mathrm{H}$. pylori negative patients had endoscopic scores of 3 or 4 (p $<0.05, \mathrm{CL}-33+11 \%)$. In this trial $60 \%$ of significant gastric lesions (score 3-4) occurred in uninfected patients; this finding supports the hypothesis that most NSAIDs gastric lesions develop through mechanisms that do not require the presence of $\mathrm{H}$. pylori. Our data are not in contrast with recent reports, suggesting that $H$. pylori not only is unimportant but may rather play a somewhat protective role.

Conclusion In this study we did not find any statistically significant correlation between $\mathrm{H}$. pylori status and NSAIDs gastrolesivity. However, most gastric lesions (60\%) occurred in H. pylori negative patients, suggesting that the presence of the infection is not a risk factor for the occurrence of NSAIDs related gastric lesions.

\section{FRI0041 IMPROVEMENTS IN FUNCTIONAL STATUS DUE TO ANAKINRA THERAPY IN PATIENTS WITH RHEUMATOID ARTHRITIS WHO ARE NOT USING DMARDS}

${ }^{1} \mathrm{P}$ Emery, ${ }^{2} \mathrm{JM}$ Woolley, ${ }^{2} \mathrm{WW}$ Chan. ${ }^{1}$ Rheumatology and Rehabilitation Research Unit, University of Leeds, Leeds, UK; ${ }^{2}$ Amgen Inc., Thousand Oaks, USA

\subsection{6/annrheumdis-2001.1170}

\section{Background}

Objectives To evaluate the effect of anakinra on the functional status of subjects with rheumatoid arthritis who were not using DMARDs.

Methods In a 24-week, multicenter, randomised, double-blind clinical trial conducted in Europe, 473 subjects received either one of three doses of anakinra $(30 \mathrm{mg}, 75 \mathrm{mg}$, or $150 \mathrm{mg}$ ) or placebo SC QD. Subjects were excluded if they used DMARDs within six weeks of entry, or if they had failed therapy with more than three DMARDs. Functional status was measured by the HAQ, which was administered at baseline and at weeks 12 and 24. The mean change in HAQ score was compared between subjects receiving anakinra (all doses combined) and those on placebo. All subjects who completed at least one post-baseline 